\title{
An Experimental Analysis of Errors in Light of Language Learning and Language Use and the Role of Executing Involvement to Increase Motivation in the English Language Classroom
}

\author{
Mohsen Fatehi*, Omid Akbari \\ Imam Reza International University, English Department, Mashhad, Iran \\ *E-mail address: Fatehi4156@gmail.com
}

Keywords: Error Analysis; language learning; language use; Contrastive Analysis; English as a foreign language; motivation; involvements to increase motivation

\begin{abstract}
People are very likely to make mistakes during language learning, $\mathrm{C}$ lear ars abo all. We want in this paper to make an experimental effort to describe and ph in learn s? errors in language learning and language use hoping it will pave the ground or $\mathrm{F} L \mathrm{le}$. ars' to have a better understanding of the errors they make. And yet all researches empirica ntil present day show a correlation between students' motivation and learning term in the Ceaching of English in ESL and EFL contexts. Notwithstanding of a sound thes cal fram rk, there are few studies which bring about strategies intended to increase motiva on and report fin ings.

This paper also endeavors to enlighten the facto which put students' motivation in jeopardy and act as hindrance in efficient foreign language 1 ning. It e uips teachers with a tool for assessing students' motivation so that they put into pra eff cive motivation strategies in the English classroom. The strategies and involve suggested can be used by teachers in copious teaching situations after of course considerin an $\mathrm{g}$ their own teaching contexts under advisement.

\section{INTRODUCTION}

Human beings are to $\mathrm{m}$ anms s. Speaking and making mistakes are exclusive features of humans, thus these feature st empha bow unique humans really are. The simplest definition of Error Analysis woul be lo vage erro as an unsuccessful bit of language. Error Analysis is the process of determini the inch nature, causes and consequences of unsuccessful language. The uniqueness of Erro Analysis, iferentiating it from Contrastive Analysis, was that the mother tongue was not anose enter the picture. Errors could be fully described in terms of the Target Language, withou need t iefer to the L1 of the learners. The Error Analyst's end of enquiry is the Forei nguag aro cr's ignorance of the Target Language. This ignorance can be shown in two $\mathrm{y}$ s. Fi $t$ in sile, then in the way they compensate for their ignorance, i.e. substitutive languas $W$ distinguish two sorts of silence: cultural silence and avoidance. Cultural silence cat $\checkmark$ by EL2 learners from 'silent cultures' while avoidance is induced by ignorance. But learners usua prefer to try to express themselves in the TL by alternative means: such as borrowing or stealing.
\end{abstract}

\subsection{Error Recognition}

In EA we assemble a line-up of utterances produced or processed by a learner and ask the 'witness' or knower to pick out the one or ones that look out of the ordinary, that is , those which are potentially wrong. One may think error detection is simple, but in fact it is just the opposite. It is interesting to find out that spotting an error in spoken, informal language is far harder than in written, formal texts. In addition, spotting one's own errors is more difficult than spotting others'. Even the native speakers sometimes have trouble detecting errors correctly. 


\subsection{Errors Pinpointing}

Error location is not always so vivid; some errors are dispersed all around the sentence or larger units also known as global errors. Burt and Kiparsky (1972) suggest that we should identify errors by reference to the TL. And there is a reasonable suggestion: the learners first need to stop making the error, and then start to produce the TL form. Gatbonton (1983) adopts the gradual dispersion model of language change, which suggests that learning involves two stages: the first is the learning stage and the second involves uprooting all the old and wrong learning so only the good ones are left.

\subsection{Characterizing Errors}

There are two reasons why the standard EA practice of describing the learner's ermoshould be in terms of the TL: First of all, learner's language and TL are co-dialects of the ome la age, so they should be describable in terms of the same grammar. Secondly, E is TL-ori ed. According to Corder (1981), the system used for the description of learner' erro must bo one having two essential characteristics: 1) the system must be well-develope, and high, lab ated, since many errors made by even beginners are remarkably complex. 2 The $\mathrm{s}$ am sh ad be as simple, self-explanatory and easily learnable as possible. Because of he charact stics James (1990) points out that Chomsky's Universal Grammar has little usa e for desu ing 1 arner errors.

\section{STAGES OF ERROR}

In this part, we investigate three stages of lan sage: the leve of substance, text and discourse. If the learner was operating the phonological or the graphological substance systems, that is spelling or pronouncing, we say he or she has prod d an encoling or decoding error. If he or she was operating the lexico-grammatical systems of th to pro uuce or process text, we refer to errors on this level as composing or unders ding errow the or she was operating on the discourse level, we label the errors occurring mi torn ion or misprocessing errors.

\subsection{Misspellings}

There are four types of miss elling he first $c$ is punctuation errors, among which the most frequent are overuse of the evcla io some writers; misordering of closing inverted comas; under or overuse o capitals, ver inclusion of a comma between an antecedent and a restrictive relative clause a misselect 1 the colon instead of the comma after the salutation in letters. The second one typ phic errors. People who are normally good spellers might be poor typists. Their proble ans in auton zing the required temporal and spatial mechanisms that underlie skilled fingering the thewriter, or keystrokes on the word-processor.

\subsection{LexicalErron.}

Acory to Ch (1980) lexis is sharply different from grammar. Grammar is said to be organ in osed sys ems, to be systematic and regular. Lexis is, by contrast, said to consist of open sy a regular and unsystematic. Recently, lexis has begun to take a central role in language s. There are a number of reasons for this. First, the boundaries between lexis and grammar are $o \mathrm{~W}$ seen to be less clear-cut than was assumed. Morphological aspects of words, which used to be treated as part of grammar, can just as well be viewed as part of the word: e.g. words of different form classes can be derived from the same root. Secondly, learners themselves believe that vocabulary is very important in language learning. Though this view may not be correct, it is likely to influence learning. Thirdly, for some learner groups, lexical errors are the most frequent category of error. Finally, vocabulary carries a particularly heavy functional load. We classify lexical errors from two perspectives: formal errors and semantic errors. Formal errors of lexis include formal misselection, misformations and distortions. Semantic errors in lexis refer to confusion of sense relations and collocational errors. 


\subsection{Pragmatic Errors.}

Pragmatic errors involve putting linguistic knowledge into practice, so we may call them pragmalinguistic deviations. They arise when ever speakers misencode a message, not to the detriment of its meaning but to the detriment of its pragmatic force, that is, what speech act it is intended to perform or what rhetorical force it should carry. Thomas (1983) calls it sociopragmatic failure. Sociopragmatic failures result from culture-clashes, from cultural differences of view concerning what is the appropriate social behavior in certain settings.

\subsection{Detecting Errors}

James (1990) once commented on the desirability of distinguishing between error description and error diagnosis. There is widespread acceptance of this principle: Dulay, Burt and Krashen (1982) clearly state that 'the accurate description of errors is a separate activity f om tho $k$ of inferring the sources of those errors. The ultimate cause of error is ignorance of TL item a hed at. It is worth noting that any formal deviance can have either declarative pro sural ca ses. When the required TL item is unknown and the learner borrows an L1subst ute, the co que ice is an L1 transfer error, but when the learner knows the TL item but fai to acc it anstead accesses an L1 substitute, we have a case of an L1 interference mista

\subsection{Motivation}

It is unanimously accepted in the related literature tha mot ion is positively linked to foreign language acquisition (Gardner, 1985). Motivation o m second ymportant determinant of educational success, with the first being aptitude, a earner's cognitiv capacity (Skehan, 1989: 38). Contemporary views recognize that motivation a complex phenomenon, and that many personal, social, and contextual parameters exist. $\mathrm{M}$ definit ons of motivation have been recommended in the relevant literature. Acce-ding to so urchers, motivation refers to the initiation, direction, intensity, persistence, and a behavior, especially goal-directed behavior (Maehr and Meyer, 1997). Brophy (2004) de nes stu motivation as "the degree to which students invest attention and effort" Dörnyei 2001) suggests that motivation includes three elements: why people, how hard ana ow lon people are eager to engage in an activity. Nevertheless, in spite of the fact the a is a streng literature on motivation and many resources available to tutors that provid rato so mure motivation, there is lack of studies which, apart from suggesting practical s tegies to in the classroom and ar ess efficien, of these classroom involvements. The purpose of this paper is to bridge thi e barch o between theory and practice, and in so doing to provide teachers with real world s ggestions whic ney can use after taking into account their specific teaching situation and dents' 'emands? The following motivation theories reflect research in both educational psych $y$ and reign language. According to the social cognitive expectancy-value model of ievem mo vation, learners' "achievement outcomes", including effort, task or course oersis hee and erformance (Wigfield and Eccles, 2000:107), are dependent on a) the degree $\mathrm{vb}$ are confident that they will experience success with reasonable effort, and b) the des to which they value and appreciate success and subsequent benefits. Central to the social cognt theory is the concept of self-efficacy. Learners' perceived self-efficacy of their capabilities to accomplish "designated types of performances" affects effort, confidence, and persistence Bandura (1986:391). Attribution theory of motivation claims that the perceived causes of educational outcomes, called attributions, impact heavily on achievement behavior and on expectations for success. Attributions are categorized along three elements: stability, locus, and control (Weiner, 1986). Stability refers to how stable the attribution is over time. In relation to locus and control, when learners attribute unsuccessful performance to factors outside their control, or external to them (e.g. ability, or an easy task), rather than to controllable, or internal causes (e.g. effort, or preparation), they develop low expectancies for success, showing little effort and persistence. Self-determination theory claims that people have a need for autonomy, competence and relatedness. Students with intrinsic motivation participate in learning activities in which "the 
sole rewards are the spontaneous feelings of interest and enjoyment" (Deci and Moller, 2005:582). Intrinsically motivated learners are more likely to attain higher levels of achievement than extrinsically motivated students, who are motivated from rewards associated with success (Gardner, 1988: 106). Goal orientation theory incorporates both cultural parameters of behavior and cognitive processes (Thrash and Elliot, 2001). It challenges that students who adopt mastery goal orientations engage in educational activities with a focus on acquiring knowledge or skills, believe in the relationship between effort and outcome, and are oriented toward "improving their level of competence" (Ames, 1992). Mastery goals are associated with an intrinsic interest in learning, and positive attitudes towards learning. In contrast, students who adopt performance goals are principally concerned with self-worth (Covington, 1984), and recognition as good students. They often avoid challenging tasks, give up easily and lack confidence in their ability. Anding to Covington's (1992) self-worth theory, the need for self-worth is a basic human ned, so lents often behave in ways to protect their self-worth. For example, they may procras te studyi for an exam, so that they can attribute failure to lack of effort, rather than lack of at $\mathrm{v}$, since this could damage their self-image. Students may also adopt reputation-saving s ategies, st as etting unrealistically high learning goals, or simply choosing not to participa Gard 's (1) social psychological approach highlights the role of attitudes towards L2 as dee rant of ótivation to learn. It stresses the link between language and culture, and concer ualizes th integ ative motive" in terms of: a) integrativeness (disposition toward L2 commun cy, attitude ard the learning situation, and c) motivation.

\subsection{Classroom Involvement}

The following motivational strategies were implemente A. Establishing a Learning Community and a Supportiv

It is a central point in all motivation theories hat creatin environment for "optimal motivation" (Alderm was) is important. For example, we should try to foster the belief that the teacher is there to pro ide alr dents with help in their learning efforts, and not to ignore, rebuke, or sneer them-This is a reved through negotiating with the students a set of classroom rules. Making fun $0^{f} \mathrm{ar}$ hg ans $\mathrm{r}$, is not accepted, and a standard of "mistake tolerance" is endorsed. Errors ar side ed a naty ral part of learning a foreign language (Dörnyei, 2001: 42).

\section{B. Providing Indirect, rath than Dires sorection}

In order to make writin fec 'ck less ty eatening to students' self-esteem and reduce anxiety, in writing tasks it is bet prom tudents about the location and the nature of errors by means of a correction code (1/e 1997:466). S ents should be prompted about the nature of their mistake by means of symb (Byr 1988). Similarly, in speaking tasks teachers should avoid over detailed, constant immedia rrection since it can undermine their confidence, and it discourages learners who are tonscio boy seeming alliterated to experiment with new language (Lightbown and Spada 999:- ).

C. Man U Experiences and Lives

In order ngrade learning goals rather than work-avoidant goals or passive participation, there should be da tasks, or altered course book activities so that students are provided with genuine chances to us the target language and engage in purposeful communication, using their experiences and opinions.

\section{Providing Opportunities for Group Work}

The incorporation of short-term projects in the classroom is of importance, because with projects students are more personally involved in the learning process, are less concerned with self-worth protection, and are motivated by a solid intent product. Project work encourages autonomy, imagination and creativity (Hedge, 2000), and students realize that they can be successful if they put effort, cooperation, or persistence in their work. 


\section{E. Using Individual Criterion-referenced Grading Standards}

The students' progression should be measured rather than their performance in relation to their classmates, while portfolios are used for the evaluation of students' progress. Face threatening activities, such as comparison of ability is to be avoided, because such practices can negatively influence low achievers in a number of ways, such as "avoidance of risk taking, use of less effective or superficial learning strategies, and negative affect directed toward the self" (Ames, 1992: 264). In order to promote effort, rather than ability attributions, Students are to be provided with effort feedback, showing to them that they can perform better if they try harder (Dörnyei, 2001: 121).

G. Personalizing the Curriculum and Supplementing the Teaching Material

Apart from the course book students have, they should be provided with tasks with assignments and activities that are at a challenging level of difficulty, but could be successfully commed with reasonable effort (Csikszentmihalyi, 1993). Students' parents are to be informed tha supple. tary materials are designed to help, and not to punish their children for their $\mathrm{y}$ perform ce. According to Brophy (2004) engaging parents in their children's progress is a racterist of successful teachers.

\section{H. Increasing Expectancies of Success}

This involves "consciously arranging the conditions" (Dörnyei, 20\% or suce ss. Pre-task activities provide students with enough assistance, and potential s stacles th amp cing tasks are removed by addressing them in advance (e.g. modeling effectiy s. ogies). To auce test anxiety, students should be given sufficient advance warning and beii orme out test specifications and assessment criteria. Of course, the above involvements 0 - $\mathrm{rra}_{\mathrm{p}}$. For ex a $1 \mathcal{c}$, both communicative activities and participation in projects increase autonom and involvemen, while most of the above involvements reduce language fear. Executing involve ent to nurt/re student motivation is not a straightforward process. First, educators are faced unima inable resources that provide recommendations to boost learning motivation. The pl lies in determining the suitable classroom involvements for a specific teaching education system and curriculum. Second, the results of involvements are time consumin se com crs need to show tenacity and solidity. English teachers should also be flexible-nough s that they constantly evaluate the effectiveness of involvements, come up with workgas, a incorpo ate changes in their motivation strategies.

\section{CONCLUSION}

Error analysts claim learners 1 , to a large degree, are not caused by the influence of their L1; instead, their rrors fect sone common learning strategies. EA tries to find out the regular things in th pucess of ion language learning through the study of learners' errors. In the case of moti ation should ay the scholastic implications are cloudless. First, although all motivational tho s i corpo ate useful elements, motivation is such a complex phenomenon, that no single theory is equate Educators need to make a synthesis, incorporating elements from many th oro 1 app $\mathrm{b}$ in their everyday classroom practice. The second implication is that theor ac on by to cther, so before employing strategies to nurture motivation, teachers should get to kt ants, their families, their social and cultural background, the value they attach to knowle of the English language, in order to enlighten the reasons that underlie their willingness to ngage in learning activities. English teachers should be aware that what motivates students in one setting may prove to be ineffective in a different one (Schunk et al, 2008:40).

\section{References}

[1] Alderman, M., K. (2004). Motivation for Achievement. Mahwah NJ: Lawrence Erlbaum.

[2] Ames, C. (1992). Classrooms: Goals, structures, and student motivation. Journal of Educational Psychology 84, 261-271.

[3] Bandura, A. (1986). Social foundations of thought and action: A social cognitive theory. Englewood Cliffs, NJ: Prentice Hall. 
[4] Brophy, J. (2004). Motivating Students to Learn. New Jersey: Lawrence Erlbaum Associates.

[5] Byrne, D. (1988). Teaching Writing Skills. London: Longman.

[6] Covington, M. V. (1992). Making the Grade: a self-worth perspective on motivation and school reform. Cambridge: Cambridge University Press.

[7] Covington, M. V. (1984). The motive for self worth. In R. Ames \& C. Ames (Eds.), Research on motivation in education: Student motivation. San Diego, CA: Academic Press, pp. 77-113.

[8] Csikszentmihalyi, M. (1993). The evolving source: A psychology for the third millennium. New York: HarperCollins.

[9] Deci, E., L., \& Moller, A., C. (2005). The concept of competence: A startirace for understanding intrinsic motivation and self-determined extrinsic motivation. 1 A. J. L t $\&$ C. S. Dweck (Eds.). Handbook of competence and motivation. New Yor y yildford ess, pp. 579-597.

[10] Dörnyei, Z. (2001). Motivational Strategies in the Language Class om. oridge: Cambridge University Press.

[11] Gardner, R. C. (1988). The socio-educational model of secon angr age learning: Assumptions, findings, and issues. Language Learning 38 a 26.

[12] Gardner, R. C. (1985). Social psychology and second gage lo ing; The role of attitudes and motivation. London: Edward Arnold.

[13] Gardner, R., C. \& MacIntyre P., D. (1993). A tudent's cortributions to second-language learning. Part II: Affective variables. Language To hing 26, 111.

[14] Hedge, T. (2000). Teaching and lear in the suage classroom. Oxford: Oxford University Press.

[15] Lee I. (1997).ESL learners' performance in ror correction in writing: some implications for teaching, System 25 (4), 465-4 1.

[16] Lightbown, P. \& and Spara, (1 a) How Languages are Learned (2nd edition).Oxford: Oxford University Pre

[17] Maehr, M., \& Meye , 1997). Un standing motivation and schooling: Where we've been, where we are, and yere need to go. Educational Psychology Review 9, 371-409.

[18] Patton, M. Q (2002). Qualita Re Rearch \& Evaluation Methods (3rd ed.). United States of America. ve.

[19] Schunk D., h. Sintricl, P., R., and Meece, J., L. (2008). Motivation in Education: Theory, Recear and A ations (3 ${ }^{\text {rd }}$ ed.)., Englewood Cliffs, NJ: Merrill/Prentice Hall.

[20] S. an (1089). Individual Differences in Second Language Learning. London: Edward Arn

[21] Thrash, , and Elliot, A. (2001). Delimiting and integrating achievement motive and goal constructs. In A. Efklides, J. Kuhl, and R. Sorrentino, (Eds.), Trends and prospects in motivation research. Boston: Kluwer, pp 3-21.

[22] Weiner, B. (1985). An attributional theory of achievement motivation and emotion. Psychological Review 92 (4), 548-73.

[23] Weiner, B. (1986). An attributional theory of motivation and emotion. New York: SpringerVerlag.

[24] Wigfield, A., \& Eccles, J., S. (2000). Expectancy-value theory of achievement motivation. Contemporary Educational Psychology 25, 68-81. 
[25] Burt, M. and Kiparsky, C. (1972). The Gooficon: A Repair Manual for English. Newbury House, Rowley, MA.

[26] Carney, E. (1994). A Survey of English Spelling. Routledge, London.

[27] Chomsky, N. (1980). Rules and Representations. Blackwell, Oxford.

[28] Corder, S.P. (1981). Error Analysis and Interlanguage. Oxford University Press, Oxford.

[29] Dulay, H., Burt, M. and Krashen, S.D. (1982). Language Two. Newbury House, Rowley, MA.

[30] Gatbonton, E. (1983). Patterned phonetic variability in second language speech: a gradual diffusion model, in B.W. Robinett and J. Schachter (eds), Second Language Learning: Contrastive Analysis, Error Analysis and Related Aspects. University of Michigam Ann Arbor, MI. pp. 240-55.

[31] James, Carl. (1990). Learner language, Language Teaching Vol. 23 No. 4: 20

[32] James, Carl and Garrett, P. (eds) (1991). Language Awareness in th Classroo Jon gman, London.

[33] Stenson, N. (1983). Induced errors, in B.W. Robinett and J. Sch at ter Q), Secd Language Learning: Contrastive Analysis, Error Analysis and Relate rpects. Un ro ty of Michigan Press, Ann Arbor, MI. pp. 256-71.

[34] Thomas, J. (1983). Cross-cultural pragmatic failure,

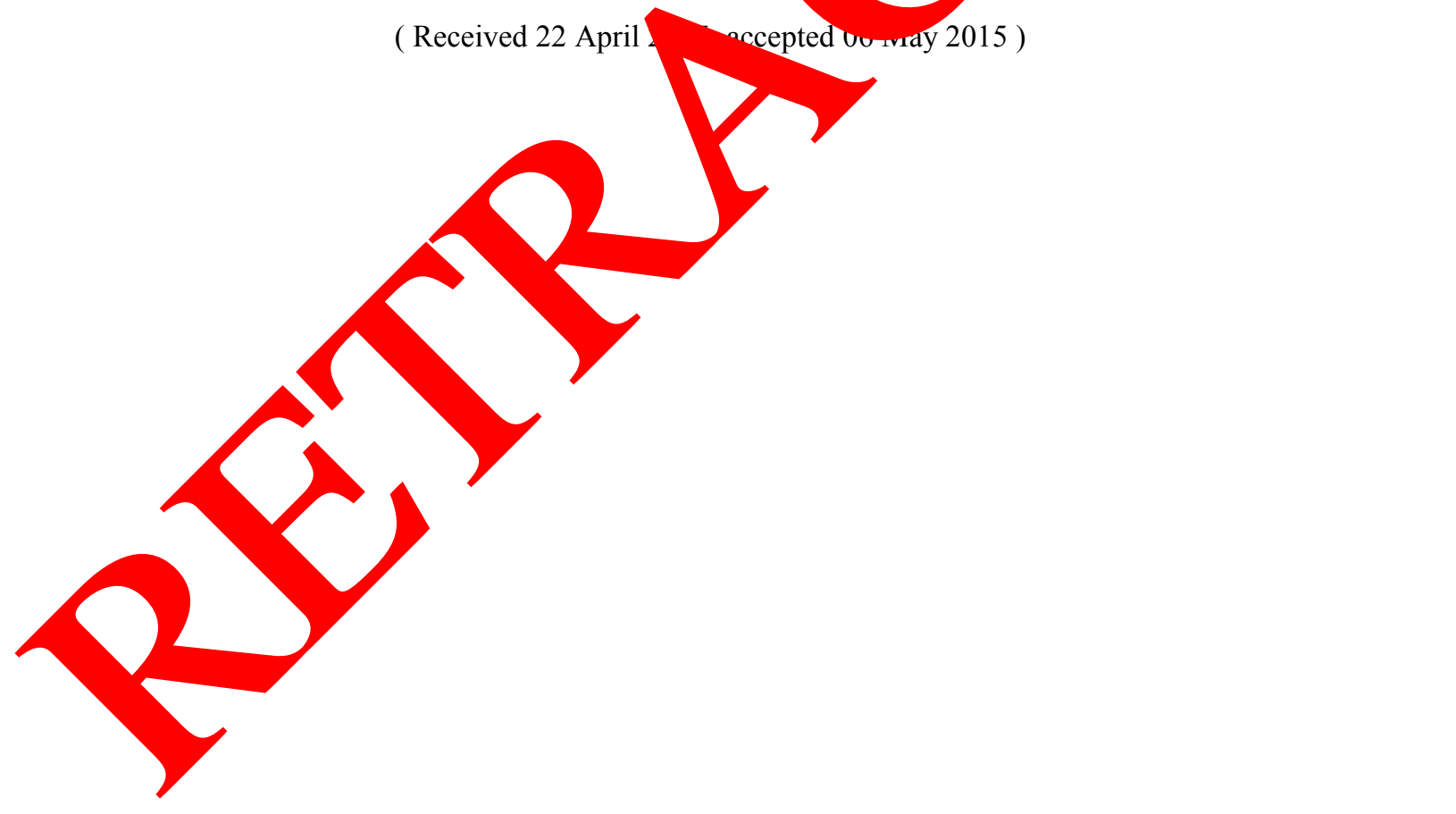

